\title{
Biomechanical modulation of collagen fragment-induced anabolic and catabolic activities in chondrocyte/agarose constructs
}

Tina T Chowdhury*1, Ronny M Schulz2, Sonpreet S Rai1 , Christian B Thuemmler2, Nico Wuestneck², Augustinus Bader2 and Gene A Homandberg ${ }^{3}$

\begin{abstract}
Introduction: The present study examined the effect of collagen fragments on anabolic and catabolic activities by chondrocyte/agarose constructs subjected to dynamic compression.

Methods: Constructs were cultured under free-swelling conditions or subjected to continuous and intermittent compression regimes, in the presence of the N-terminal (NT) and C-terminal (CT) telopeptides derived from collagen type II and/or $1400 \mathrm{~W}$ (inhibits inducible nitric oxide synthase (iNOS)). The anabolic and catabolic activities were compared to the amino-terminal fibronectin fragment $\left(\mathrm{NH}_{2}-\mathrm{FN}-\mathrm{f}\right)$ and assessed as follows: nitric oxide (NO) release and sulphated glycosaminoglycan (sGAG) content were quantified using biochemical assays. Tumour necrosis factor-a (TNFa) and interleukin-1 $\beta$ (IL-1 $\beta$ ) release were measured by ELISA. Gene expression of matrix metalloproteinase-3 (MMP-3), matrix metalloproteinase-13 (MMP-13), collagen type II and fibronectin were assessed by real-time quantitative polymerase chain reaction (qPCR). Two-way ANOVA and the post hoc Bonferroni-corrected $t$-test was used to examine data.
\end{abstract}

Results: The presence of the NT or CT peptides caused a moderate to strong dose-dependent stimulation of NO, TNFa and IL-1 $\beta$ production and inhibition of sGAG content. In some instances, high concentrations of telopeptides were just as potent in stimulating catabolic activities when compared to $\mathrm{NH}_{2}-\mathrm{FN}-$ f. Depending on the concentration and type of fragment, the increased levels of $\mathrm{NO}$ and cytokines were inhibited with $1400 \mathrm{~W}$, resulting in the restoration of sGAG content. Depending on the duration and type of compression regime employed, stimulation with compression or incubation with $1400 \mathrm{~W}$ or a combination of both, inhibited telopeptide or $\mathrm{NH}_{2}-\mathrm{FN}-$ f induced $\mathrm{NO}$ release and cytokine production and enhanced sGAG content. All fragments induced MMP-3 and MMP-13 expression in a time-dependent manner. This effect was reversed with compression and/or $1400 \mathrm{~W}$ resulting in the restoration of sGAG content and induction of collagen type II and fibronectin expression.

Conclusions: Collagen fragments containing the $\mathrm{N}$ - and C-terminal telopeptides have dose-dependent catabolic activities similar to fibronectin fragments and increase the production of NO, cytokines and MMPs. Catabolic activities were downregulated by dynamic compression or by the presence of the iNOS inhibitor, linking reparative activities by both types of stimuli. Future investigations which examine the signalling cascades of chondrocytes in response to matrix fragments with mechanical influences may provide useful information for early osteoarthritis treatments.

\section{Introduction}

The ability of degradation products of the extracellular matrix to regulate cartilage homeostasis and influence

* Correspondence: t.t.chowdhury@qmul.ac.uk

1 School of Engineering and Materials Science, Queen Mary University of London, Mile End Road, London, E1 4NS, UK

Full list of author information is available at the end of the article osteoarthritis (OA) disease progression has been extensively studied [1,2]. For instance, different types of matrix fragments derived from fibronectin or collagen can signal and amplify catabolic processes in chondrocytes that act to either remove tissue components for repair or to initiate reparative signals $[3,4]$. Chondrocytes will additionally respond to biomechanical perturbation such that 
mechanical loading on normal or diseased tissue will contribute to signalling cascades and upregulate synthetic activity or increase the levels of inflammatory mediators [5-7]. Our understanding of what factors initiate the early phase of matrix damage in $\mathrm{OA}$ is poor. The question of whether mechanical loading modulates matrix fragment induced mechanisms for repair and/or degradation in early stage OA is not known.

The inflammatory pathways induced by fibronectin fragments (FN-fs) in chondrocytes are well characterised $[8,9]$. For instance, the amino-terminal fibronectin fragment $\left(\mathrm{NH}_{2}-\mathrm{FN}-\mathrm{f}\right)$ has potent catabolic activities and was shown to increase cytokines (interleukin-1 $\alpha$ (IL-1 $\alpha$ ), interleukin-1 $\beta$ (IL-1 $\beta)$, tumour necrosis factor- $\alpha$ (TNF $\alpha)$, interleukin-6 (IL-6)), matrix metalloproteinases (matrix metalloproteinase-3 (MMP-3), matrix metalloproteinase13 (MMP-13)) and nitric oxide (NO) production in human and bovine cartilage [10-14]. The signalling pathways involve the mitogen activated protein kinase (MAPK) and nuclear factor-kappa B (NFK B) cascades mediated by stimulation of integrin receptors, leading to a suppression of proteoglycan synthesis and increased proteoglycan depletion in chondrocytes [15-19]. In addition, the N-terminal (NT) telopeptide from collagen type II was shown to upregulate MMP-3 and MMP-13 levels in human and bovine cartilage [20-22]. However, collagen fragments (Col-fs) containing the NT or C-terminal (CT) telopeptide regions were much slower at increasing MMP levels when compared to the $\mathrm{NH}_{2}$ - $\mathrm{FN}-\mathrm{f}$ [23]. This difference could be reflected in the differential rate of activation of members of the MAPK or NFKB family, leading to the production of common catabolic mediators such as NO [19]. Recently, we showed that compressive loading inhibits $\mathrm{NH}_{2}-\mathrm{FN}-\mathrm{f}$ induced $\mathrm{NO}$ production and restores matrix synthesis in chondrocytes cultured in agarose constructs [24]. It is plausible that mechanical loading competes with the catabolic pathways induced by the matrix fragments and contributes to early reparative signals in chondrocytes. The present study therefore compared the effect of Col-fs with the $\mathrm{NH}_{2}$-FN-f on the production of NO, cytokines and MMPs in chondrocyte/ agarose constructs subjected to dynamic compression.

\section{Materials and methods}

\section{Chondrocyte isolation and culture in agarose constructs}

Articular cartilage was harvested from the porcine metacarpalphalangeal joints of freshly slaughtered 12-monthold pigs from a local abattoir (FEL GmbH, Leipzig, Germany). Cartilage tissue was pooled from six joints, diced and incubated on rollers for one hour at $37^{\circ} \mathrm{C}$ in Dulbecco's Modified Eagle's Medium (DMEM) supplemented with $10 \%(\mathrm{v} / \mathrm{v})$ foetal calf serum (FCS) $+2 \mu \mathrm{M} \mathrm{L}$ glutamine, $5 \mu \mathrm{g} \cdot \mathrm{ml}^{-1}$ penicillin, $5 \mu \mathrm{g} \cdot \mathrm{ml}^{-1}$ streptomycin,
$20 \mathrm{mM}$ Hepes buffer, and $0.05 \mathrm{mg} / \mathrm{ml} \mathrm{L}$-ascorbic acid + 700 unit. $\mathrm{ml}^{-1}$ pronase, and incubated for a further 16 hours at $37^{\circ} \mathrm{C}$ in DMEM $+10 \%$ FCS (all from SigmaAldrich, Taufkirchen, Germany) supplemented with 2 mg. $\mathrm{ml}^{-1}$ collagenase A (Biochrom KG, Berlin, Germany). The cell suspension was washed and viable chondrocytes counted using a haemocytometer and trypan blue. Cells were finally resuspended in medium at a cell concentration of $8 \times 10^{6}$ cells.ml $^{-1}$ using established methods $[25,26]$. Briefly, the cell suspension was added to an equal volume of molten $6 \%(\mathrm{w} / \mathrm{v})$ agarose type VII in Earle's Balanced Salt Solutions (EBSS) to yield a final cell concentration of $4 \times 10^{6}$ cells.ml $^{-1}$ in $3 \%(\mathrm{w} / \mathrm{v})$ agarose (Sigma-Aldrich, Taufkirchen, Germany). The chondrocyte/agarose suspension was transferred into a sterile stainless steel mould, containing holes $10 \mathrm{~mm}$ in diameter and $3 \mathrm{~mm}$ in height and allowed to gel at $4^{\circ} \mathrm{C}$ for 20 minutes to yield cylindrical constructs. All constructs were maintained in culture in $1 \mathrm{ml}$ of DMEM + 10\% FCS at $37^{\circ} \mathrm{C}$ in $5 \% \mathrm{CO}_{2}$ for 24 hours.

\section{Dose-response effect of telopeptides in chondrocyte/ agarose constructs}

The dose-response effect of the N-terminal (NT) and Cterminal (CT) telopeptides derived from collagen type II were examined in constructs cultured under free-swelling conditions for 48 hours. The synthetic peptides were less than $10 \mathrm{kDa}$ in size and were synthesised by Sigma Genosys (Haverhill, UK), using sequences published previously [20-23]. More specifically, the NT peptide corresponds to the amino-terminal region of collagen type II and contains 19 amino acids (residues 182 to 212) with an additional four glycine-proline-hydroxyproline (GPX) tripeptide repeat resulting in a short 31-mer peptide (sequence: QMAGGFDEKAGGAGLGVMQGPMGPMGPRGPP). The CT peptide corresponds to the carboxyl-terminal end of collagen type II and contains 24 amino acids (residues 1218 to 1241; sequence: IDMSAFAGLGPREKGPDPLQYMRA). The constructs were cultured in $1 \mathrm{ml}$ of DMEM $+1 \times$ ITS liquid media (SigmaAldrich, Taufkirchen, Germany) supplemented with either $0,0.05,0.5,5$ and $50 \mu \mathrm{M}$ NT or $0.05,0.5,5$ and 50 $\mu \mathrm{M} C \mathrm{C}$ peptide in the presence and absence of $1 \mathrm{mM} \mathrm{N}$ (3-(aminomethyl) benzyl)acetamidine.2HCL (1400 W) (Merck Biosciences, Nottingham, UK). $1400 \mathrm{~W}$ is a chemical inhibitor which specifically inhibits the inducible nitric oxide synthase (iNOS) enzyme. An optimal concentration of the scrambled form of the NT (SN (19 residues; sequence: GPGAGQPGKGRGPAPLQFGMAMMDMADPGEV)) and CT (SC (24 residues; sequence: MARFPAMLGPARDPISYQKEGDGL)) peptides were used as negative controls (both at $50 \mu \mathrm{M}$ ). A commercially available $30 \mathrm{kDa} \mathrm{NH}$-FN-f at $1 \mu \mathrm{M}$ was used as a positive control (Sigma-Aldrich, Poole, UK). At 
the end of the culture period, the constructs and corresponding media were immediately stored at $-20^{\circ} \mathrm{C}$ prior to biochemical analysis.

\section{Application of dynamic compression}

The present study utilized a bioreactor device (Ingenieurburo, GmbH, Braunschweig, Germany) to apply compressive loading to chondrocyte/agarose constructs, using a system described previously [27]. Briefly, the bioreactor vessel consists of two chambers with a cylindrical lid that fits a magnetic actuator connected to a stainless steel loading plate (Figure 1a). Six constructs were held under confined conditions in a locating stage with an inner and outer wall (Figure 1a, inset). This arrangement limits axial movement of the loading plate therefore allowing the system to apply a known compressive strain. Both the locating stage and loading plate were fluid permeable (TECAPEEK, Ensinger GmbH and Co., Nufringen, Germany) and perforated to facilitate nutrient transport to all surfaces of the construct. The lower chamber has two ports enabling media and gas exchange while the upper chamber fits two connectors for $\mathrm{pH}$ and $\mathrm{O}_{2}$ biosensors. Culture media containing either $50 \mu \mathrm{M}$ NT or $50 \mu \mathrm{M} \mathrm{CT}$ or $1 \mu \mathrm{M} \mathrm{NH}_{2}$-FN-f and/or $1 \mathrm{mM} 1400$ $\mathrm{W}$ were introduced to the lower chamber. The vertical motion of the magnetic actuator and loading plate was controlled by a magnet field induced by an external Tesla $\mathrm{NdFeB}$ magnet which rotated above the bioreactor. Various continuous and intermittent compression regimes were employed over a 6 or 48 hour culture period resulting in a total number of compression cycles which ranged from 4800 to 172800 (Figure 1b). The following periods of compression were applied to constructs in a dynamic manner at $15 \%$ strain and a frequency of $1 \mathrm{~Hz}: 10$ minutes compression with a 5 hour 50 minutes unstrained period (10 minutes/5 hr 50×1); 1.5 hour compression with a 4.5 hour unstrained period $(1.5 \mathrm{hr} / 4.5 \mathrm{hr} \times 1)$; 6 hours of continuous compression (C6); 10 minutes compression with a 5 hour 50 minute unstrained period repeated $8 \times(10$ minutes $/ 5$ hr $\left.50^{\times 8}\right)$; 1.5 hour compression with a 4.5 hour unstrained period repeated $8 \times\left(1.5 \mathrm{hr} / 4.5 \mathrm{hr}^{\times 8}\right)$ and 48 hours of continuous compression (C48). Dynamic compression was applied with a load and displacement control feedback system. A typical response for the load and displacement profile generated with a sinusoidal waveform is illustrated in Figure 1c. This ensured a maximum load of $12 \mathrm{~N}$ which remained constant during the 48 hour compression period. The displacement curves showed similar profiles at time $=0,1$ and 48 hours and was equivalent to a deformation of $450 \mu \mathrm{M}$ and displacement of $15 \%$ strain. For control constructs, the fluid permeable loading plate was situated $0.8 \mathrm{~mm}$ above the construct to facilitate nutrient transport and cultured in an unstrained state at $0 \%$ strain for the same time period within the bio- reactor device. At the end of the culture period, all constructs and corresponding media were immediately stored at $-80^{\circ} \mathrm{C}$ prior to analysis.

\section{RNA isolation, CDNA synthesis and real-time quantitative polymerase chain reaction (qPCR)}

RNA was isolated from chondrocytes cultured in agarose using protocols described in the QIAquick Spin gel extraction and RNeasy kits, as previously described $[24,28]$. (Qiagen, Hilden, Germany). Following the manufacturer's instructions, Ambion's DNA-free DNase treatment and removal reagents were used to eliminate any contaminating DNA from the RNA sample (Ambion, Applied Biosystems, Warrington, UK). RNA was quantified on the Nanodrop ND-1000 spectrophotometer (LabTech, East Sussex, UK) and reverse transcription performed using manufacturer's protocols from the M-MLV First-Strand cDNA synthesis kit, oligo $(\mathrm{dT})_{15}$ primer and a total of $200 \mathrm{ng}$ of RNA (Promega, Manheim, Germany). For real-time quantitative PCR, the cDNA was amplified in $25 \mu \mathrm{l}$ reaction mixtures containing $1 \mu \mathrm{l} \mathrm{cDNA}, 12.5 \mu \mathrm{l}$ SYBR $^{\circ}$ Green PCR Master Mix, primer pairs (Table 1) and nuclease free PCR grade water (Applied Biosystems) using an automated PCR robot (CAS-1200 ${ }^{\mathrm{m} w}$, Corbett Research, Cambridge, UK). Each sample was run in duplicate on the 72-well thermal system of the RotorGene $^{\text {max }} 3000$ instrument (Corbett Research). Thermocycling conditions comprised of an initial polymerase activation step at $95^{\circ} \mathrm{C}$ for 3 minutes, followed by 35 cycles at $95^{\circ} \mathrm{C}$ for $30 \mathrm{~s}$, at $55^{\circ} \mathrm{C}$ for $60 \mathrm{~s}$ and at $72^{\circ} \mathrm{C}$ for $60 \mathrm{~s}$. Following amplification, a melt curve was obtained to ensure no detection of primer-dimers and non-specific products. In order to screen for contamination of reagents or false amplification, PCR controls were prepared for each sample by preparing identical reaction mixtures except for the addition of the template (NTC). No reverse transcriptase (NoRT) controls were additionally included in each PCR assay.

Fluorescence data were collected during the annealing stage of amplification and data were analysed using the RG-3000 ${ }^{\text {min }}$ qPCR software (version 6, Corbett Research). Baselines and thresholds were automatically set by the RG-3000 $0^{\text {ma }}$ qPCR software and used after manual inspection. The cycle threshold $\left(C_{t}\right)$ value for each duplicate reaction was expressed as the mean value and the results were exported into Microsoft Excel for further analysis. The data obtained by PCR assay for Glyceraldehyde-3Phosphate Dehydrogenase (GAPDH) were validated as a reference gene by displaying the $C_{t}$ values as Box and Whisker plots and the distribution examined under mechanical loading conditions (data not shown). The $\mathrm{C}_{\mathrm{t}}$ values for GAPDH remained stable with no changes detected under all treatment conditions, suggesting its 
A

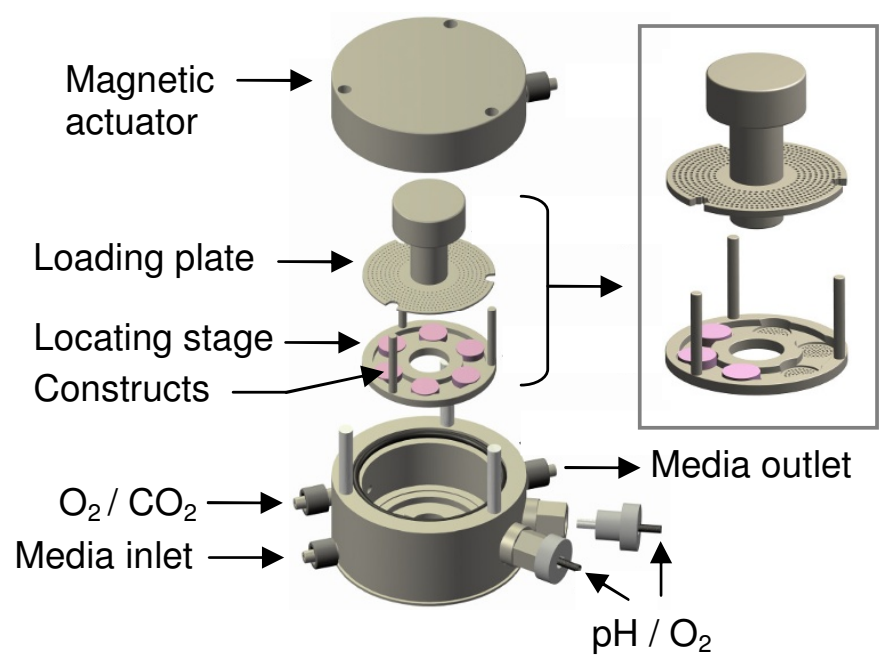

B

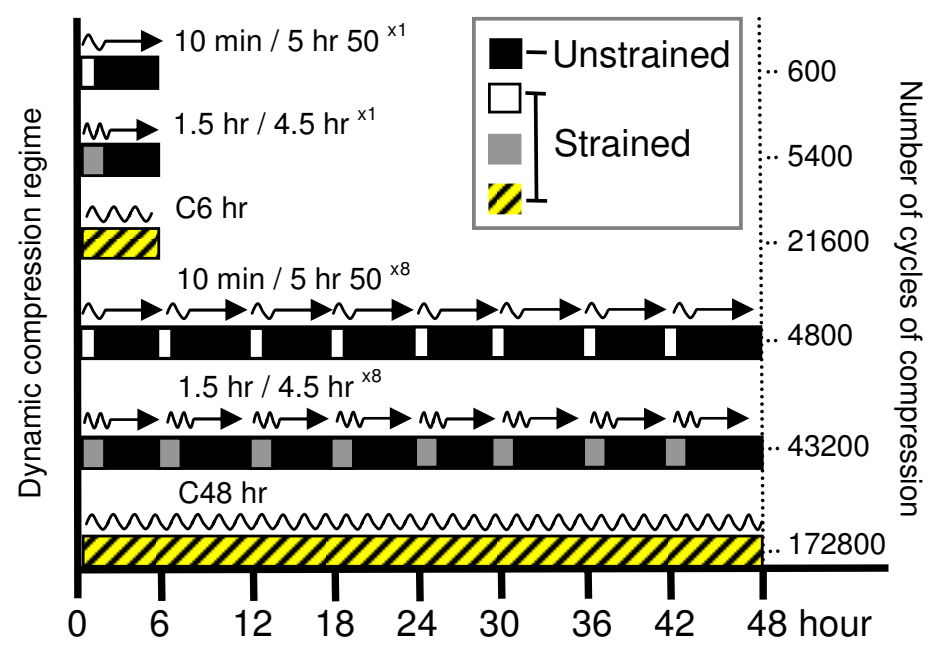

C

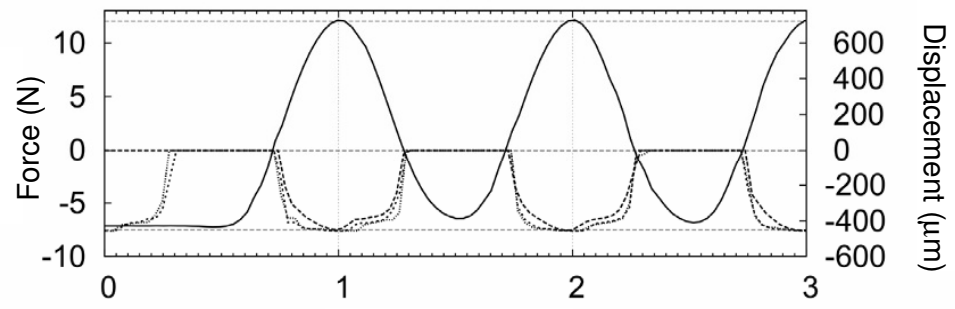

Figure 1 Schematic illustrating components of the bioreactor device and experimental compression regimes. (a) Six chondrocyte/agarose constructs were held under confined conditions in a locating stage as shown in the inset. Both the locating stage and loading plate were fluid permeable and perforated to facilitate nutrient transport to all surfaces of the construct. (b) The compression regimes are shown in the middle panel resulting in a total number of cycles ranging from 600 to 172,800 over a 6- or 48-hour culture period. Black bars indicate unstrained periods equivalent to $0 \%$ strain. (c) Black lines show typical response profiles for load and displacement generated with a sinusoidal waveform at time $=0$ (dash), 1 (dash dot) and 48 hours (square dot), respectively. 
Table 1: Description of the sequences used to quantify gene expression and real-time reaction efficiencies of PCR assays

\begin{tabular}{|c|c|c|c|c|}
\hline Gene & Gene ID & Sequences & Product size (bp) & Efficiency \\
\hline \multicolumn{5}{|l|}{ MMP-3 } \\
\hline & $\underline{396769}$ & Forward: 5'-ACCCAAGAAGTATCCACACCCT-3' & 215 & $1.98 \pm 0.06$ \\
\hline & & Reverse: 5'-TGCTTCAAAGACAGCATCCACT-3' & & \\
\hline \multicolumn{5}{|l|}{ MMP-13 } \\
\hline & $\underline{397346}$ & Forward: 5'-CCAAAGGCTACAACTTGTTTCTTG-3' & 77 & $1.99 \pm 0.03$ \\
\hline & & Reverse: 5'-TGGGTCCTTGGAGTGGTCAA-3' & & \\
\hline \multicolumn{5}{|c|}{ Collagen type II } \\
\hline & $\underline{397323}$ & Forward: 5'-CGCTGAACATCCTCACAAC-3' & 249 & $1.98 \pm 0.19$ \\
\hline & & Reverse: 5'-TCCTGTAGATACGCCTAAGC-3' & & \\
\hline \multicolumn{5}{|c|}{ Fibronectin } \\
\hline & $\underline{397620}$ & Forward: 5'-GACAGATGAGCTTCCCCAAC-3' & 752 & $2.02 \pm 0.09$ \\
\hline & & Reverse: 5'-CACTGCCAAAGCCTAAGCAC-3' & & \\
\hline \multicolumn{5}{|l|}{ GAPDH } \\
\hline & $\underline{396823}$ & Forward: 5'-AATCCCATCACCATCTTCCA-3' & 318 & $2.03 \pm 0.01$ \\
\hline & & Reverse: 5'-TGTGGTCATGAGTCCTTCCA-3' & & \\
\hline
\end{tabular}

Primers used in quantitative polymerase chain reaction (qPCR) experiments with SYBR green produced amplicons of 77 to 752 base pairs with efficiency values between 1.98 and 2.03. GAPDH, glyceraldehyde 3-phosphate dehydrogenase; MMP-3, matrix metalloproteinase-3; MMP-13, matrix metalloproteinase- 13.

suitability as a reference gene. Relative quantification of MMP-3, MMP-13, collagen type II and fibronectin signals was accomplished by normalizing each target to the reference gene, GAPDH and to the calibrator sample (unstrained, untreated sample) by a comparative $C_{t}$ approach [29]. For each sample, the ratio of target $\Delta \mathrm{Ct}$ and reference $\Delta \mathrm{Ct}$ was calculated, as shown in equation 1 .

$$
\text { Ratio }=\frac{\left(1+\mathrm{E}_{\text {Target }}\right)^{\Delta \mathrm{Ct}}{ }_{\text {Target }}(\text { MEAN Calibrator }- \text { Sample })}{\left(1+\mathrm{E}_{\text {Reference }}\right)^{\Delta \mathrm{C} t} \text { Reference }(\text { MEAN Calibrator }- \text { Sample })}
$$

Where: E represents the efficiencies obtained for the target and reference gene. $\Delta \mathrm{Ct}_{\text {target }}$ represents the difference in $\mathrm{C}_{\mathrm{t}}$ values for the mean calibrator or sample for the target gene. $\Delta \mathrm{Ct}_{\text {Reference }}$ represents the difference in $\mathrm{C}_{\mathrm{t}}$ values for the mean calibrator or sample for the reference gene, GAPDH.

PCR efficiencies for primer pairs with SYBR green were derived from standard curves $(n=3)$ by preparing a 10 fold serial dilution of cDNA from a sample which represents the untreated sample. The real-time PCR efficiencies (E) of amplification for each target was defined according to the relationship, $E=10[-1 /$ slope $]$. The $\mathrm{R}^{2}$ value of the standard curve exceeded 0.9998 and revealed efficiency values presented in Table 1.

\section{Biochemical analysis}

At the end of the experiment, constructs were digested in phosphate buffered saline (PBS) supplemented with 10 mM L-cysteine and 10 mM EDTA, pH 6.5 for 60 minutes at $70^{\circ} \mathrm{C}$ and subsequently incubated with $1.66 \mathrm{Units} / \mathrm{mL}$ agarase for 16 hours at $37^{\circ} \mathrm{C}$ and with 0.1 units $/ \mathrm{mL}$ Papain for 1 hour at $60^{\circ} \mathrm{C}$, as previously described $[25,26]$. DNA levels were determined in the agarase/papain digests by Quant-i $\mathrm{T}^{\mathrm{TM}}$ PicoGreen ${ }^{\circ}$ dsDNA assay according to manufacturer's instructions (Molecular Probes, Eugene, OR, USA). Sulphated glycosaminoglycan (sGAG) content was determined using the 1, 9-dimethyl-methylene blue dye-binding assay in agarose/papain digests and media samples and the values normalized to DNA levels $[25,26]$. The production of NO was determined in media by converting nitrate to nitrite using 1 unit.ml-1 nitrate reductase in $40 \mu \mathrm{M} \mathrm{NAPDH}, 500 \mu \mathrm{M}$ glucose 6-phosphate, 160 unit. $\mathrm{ml}^{-1}$ glucose 6-phosphate dehydrogenase and $20 \mathrm{mM}$ Tris-HCL for 15 minutes at $37^{\circ} \mathrm{C}$ and total nitrite assayed spectrophotometrically at $540 \mathrm{~nm}$ using the Griess reaction, as described previously [30,31]. The levels of IL- $1 \beta$ and TNF $\alpha$ were determined in media samples by commercial ELISA kits according to manufacturer's instructions ( $\mathrm{R} \& \mathrm{D}$ Systems Europe Ltd, Abingdon, UK). 


\section{Statistics}

For the dose-response studies, data represent the mean and standard error of the mean (SEM) values of six replicates from two separate experiments. For the mechanical loading experiments, data represent the mean and SEM values of eight replicates from two separate experiments. Statistical analysis was performed by a two-way analysis of variance (ANOVA) and the multiple post hoc Bonferroni-corrected $t$-tests to compare differences between treatment groups as indicated in the figure legend. In all cases, a level of $5 \%$ was considered statistically significant $(P<0.05)$.

\section{Results}

\section{Telopeptides increase NO production and inhibit sGAG} content in a dose-dependent manner

The ability of NT and CT peptides to influence NO release and sGAG content in constructs cultured for 48 hours are illustrated in Figure 2. The levels of NO were enhanced by the presence of the NT or CT peptides, with significant levels at $0.5 \mu \mathrm{M}$ and increasing up to $50 \mu \mathrm{M}$ when compared to untreated controls $(P<0.001$ and $P<$ 0.05 ; Figure $2 \mathrm{a}$ and $2 \mathrm{~b}$, respectively). This effect was similar to treatment with $\mathrm{NH}_{2}$ - FN-f and showed significant levels of NO production when compared to untreated controls $(P<0.001)$. At $50 \mu \mathrm{M}$, co-incubation with 1400 W inhibited telopeptide or FN-f-induced NO release with levels returning to basal values. In contrast, the presence of the NT or CT peptides did not influence sGAG content at a concentration ranging from 0.05 to $5 \mu \mathrm{M}$ when compared to untreated controls (Figure 2c, d). At $50 \mu \mathrm{M}$, the presence of the NT or CT peptides partially inhibited sGAG content $(P<0.01)$ and this effect was reversed with $1400 \mathrm{~W}$ for the NT peptide, only $(P<0.05$; Figure $2 \mathrm{c})$. The $\mathrm{NH}_{2}$-FN-f strongly inhibited sGAG content $(P<$ $0.001)$ and the response was reversed with $1400 \mathrm{~W}(P<$ $0.001)$. The control SN or SC peptides did not significantly influence NO production and sGAG content in the presence and absence of $1400 \mathrm{~W}$.

\section{Telopeptides increase cytokine levels in a dose-dependent manner}

We next characterised the dose-response effect of NT and CT peptides on the production of IL-1 $\beta$ and TNF $\alpha$ in constructs cultured for 48 hours (Figure 3 ). The presence of the NT or CT peptides enhanced TNF $\alpha$ release when compared to untreated controls, with significant levels at $5(P<0.05)$ and $50 \mu \mathrm{M}(P<0.001)$ for the NT peptide and at $0.05(P<0.05), 5(P<0.05)$ and $50 \mu \mathrm{M}(P<0.001)$ for the $\mathrm{CT}$ peptide (Figure $3 \mathrm{a}$ and $3 \mathrm{~b}$, respectively). At 50 $\mu \mathrm{M}$, peptide-induced TNF- $\alpha$ release was inhibited with 1400W $(P<0.001$; Figure 3a, b). The presence of the NT or CT peptides increased IL- $1 \beta$ production in a concen- tration-dependent manner (Figure $3 \mathrm{c}$ and $3 \mathrm{~d}$, respectively). This effect was inhibited with $1400 \mathrm{~W}$ resulting in a significant reduction at $50 \mu \mathrm{M} \mathrm{NT}(P<0.001)$ or with 5 and $50 \mu \mathrm{M}$ CT peptide (both $P<0.05$ ). The presence of the $\mathrm{NH}_{2}$-FN-f increased maximal levels of TNF $\alpha$ and IL$1 \beta$ production when compared to untreated controls and this effect was inhibited with $1400 \mathrm{~W}(P<0.001)$. The control SN and SC peptides did not influence cytokine levels in the presence and absence of $1400 \mathrm{~W}$.

\section{Dynamic compression modulates telopeptide induced NO release and restores SGAG content}

Having demonstrated that treatment with NT or CT peptides influenced NO release and sGAG production in a concentration-dependent manner, subsequent studies examined the effect of continuous or intermittent compression on the peptide or $\mathrm{NH}_{2}$-FN-f induced response (Figure 4). Under no treatment conditions, no significant differences were detected for NO release in unstrained constructs and constructs subjected to compression for 10 minutes $/ 5 \mathrm{hr} 50^{\times 8}, 1.5 \mathrm{hr} / 4.5 \mathrm{hr}^{\times 8}$ or $\mathrm{C} 48$ hours (Figure 4a). In unstrained constructs, the presence of the NT or $\mathrm{CT}$ peptides enhanced NO levels when compared to constructs cultured without the peptide (both $P<0.001$ ). Stimulation with compression for 10 minutes $/ 5 \mathrm{hr} 50^{\times 8}$, $1.5 \mathrm{hr} / 4.5 \mathrm{hr}^{\times 8}$ or $\mathrm{C} 48$ hours (all $P<0.01$ ), or incubation with $1400 \mathrm{~W}$ inhibited NO release $(P<0.001)$. This effect could be further downregulated by co-stimulation with both compression for C48 hours and $1400 \mathrm{~W}$ in peptide treated constructs $(P<0.01)$. In unstrained constructs, the $\mathrm{NH}_{2}$-FN-f increased maximal levels of $\mathrm{NO}$ release when compared to untreated controls $(P<0.001)$. This effect was inhibited under all compression regimes or culture with the iNOS inhibitor (all $P<0.001$ ). Co-stimulation with both compression for $1.5 \mathrm{hr} / 4.5 \mathrm{hr}^{\times 8}$ or $\mathrm{C} 48$ hours and $1400 \mathrm{~W}$ abolished FN-f-induced NO release with values returning to basal levels (both $P<0.01$ ).

Under no treatment conditions, sGAG content was enhanced following stimulation with intermittent compression for $1.5 \mathrm{hr} / 4.5 \mathrm{hr} 50^{\times 8}$ or with continuous compression for C48 hours (both $P<0.001$; Figure 4b). In unstrained constructs, the presence of the NT or CT peptides inhibited sGAG content (both $P<0.05$ ) and this effect was partially reversed with compression for $1.5 \mathrm{hr} /$ $4.5 \mathrm{hr}^{\times 8}$ or C48 hours and/or $1400 \mathrm{~W}$. In unstrained constructs, the $\mathrm{NH}_{2}-\mathrm{FN}-\mathrm{f}$ inhibited sGAG content when compared to untreated constructs $(P<0.001)$. This effect was reversed with compression for $1.5 \mathrm{hr} / 4.5 \mathrm{hr}^{\times 8}$ or C48 hours and/or culture with the iNOS inhibitor (all $P<$ 0.001). We did not detect significant changes in $\mathrm{NO}$ release and sGAG content in constructs cultured with the control SN or SC peptides and/or $1400 \mathrm{~W}$. 

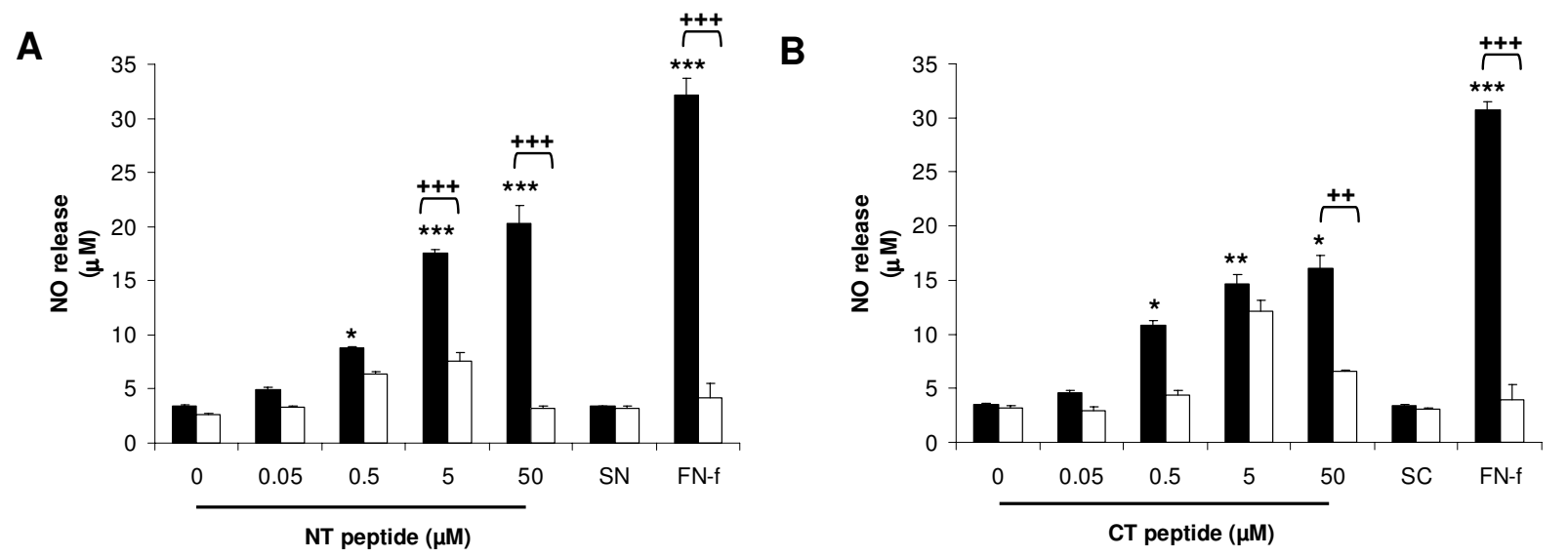

C

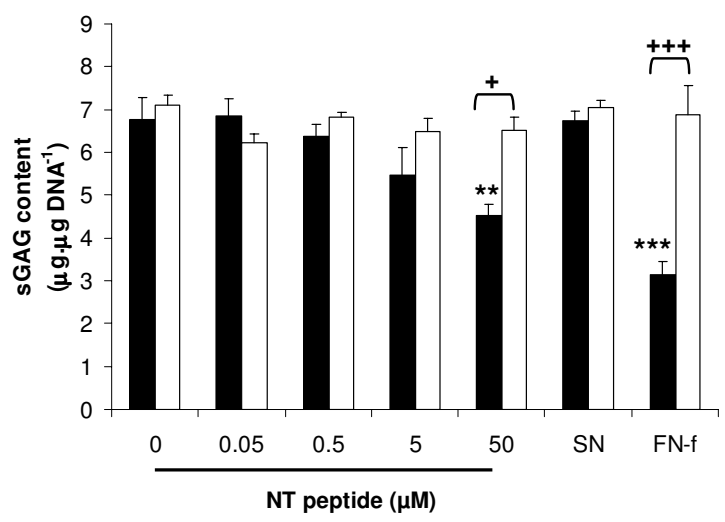

Telopeptide or FN-f
D

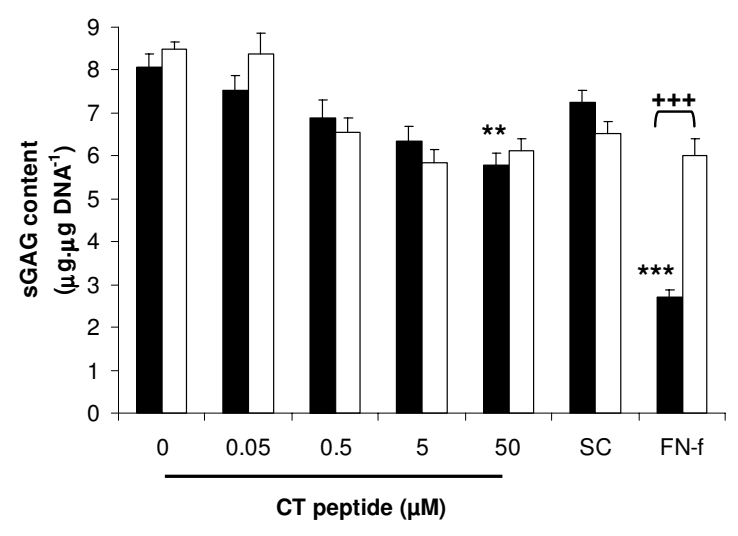

Telopeptide or FN-f + 1400W

Figure 2 Dose-response effect of NT and CT telopeptides. Constructs were cultured with NT (0.05 to $50 \mu \mathrm{M})$ or CT (0.05 to $50 \mu \mathrm{M})$ peptides under free-swelling conditions in the presence or absence of $1 \mathrm{mM} 1400 \mathrm{~W}$ for 48 hours: (a) NO release and (b) sGAG content ( $\mathrm{n}=6$ ). A scrambled form of the NT (SN) and CT (SC) peptide were used as negative controls (both at $50 \mu \mathrm{M})$. An NH $\mathrm{N}_{2}-\mathrm{FN}-\mathrm{f}(1 \mu \mathrm{M})$ was used as a positive control. $\left(^{*}\right)$ indicates significant comparisons for 0 vs fragment; $(+)$ indicates significant comparisons for fragment vs fragment $+1400 \mathrm{~W}(\mathrm{n}=6 \pm$ ).

\section{Dynamic compression inhibits telopeptide induced cytokine levels}

Figure 5 examined the effect of continuous and intermittent compression on cytokine production in the presence and absence of telopeptides or $\mathrm{NH}_{2}$-FN-f for 48 hours. Under no treatment conditions, the levels of TNF $\alpha$ or IL$1 \beta$ were not significantly influenced by compression for 10 minutes $/ 5 \mathrm{hr} 50^{\times 8}, 1.5 \mathrm{hr} / 4.5 \mathrm{hr}^{\times 8}$ or $\mathrm{C} 48$ hours. In unstrained constructs, the presence of NT or CT peptides increased TNF $\alpha$ and IL-1 $\beta$ production (both $P<$ 0.001). This response was broadly inhibited under all compression regimes and/or culture with $1400 \mathrm{~W}$. In unstrained constructs, the presence of the $\mathrm{NH}_{2}$-FN-f increased TNF $\alpha$ or IL- $1 \beta$ release. This effect was inhibited under all compression regimes and/or $1400 \mathrm{~W}$. We did not detect any significant changes in cytokine levels for constructs cultured with the control SN and SC peptides.

\section{Dynamic compression modulates telopeptide induced gene expression}

To investigate the temporal expression profile of catabolic (MMP-3, MMP-13; Figure 6) and anabolic genes (collagen type II, fibronectin; Figure 7), constructs were subjected to continuous and intermittent compression in the presence and absence of the NT and CT peptides or $\mathrm{NH}_{2}$-FN-f for 6 or 48 hours. At six hours, the $\mathrm{C} 6$ regime maximally increased MMP-3 expression when compared to unstrained constructs $(P<0.05$; Figure 6a). At 48 hours, compression for $1.5 \mathrm{hr} / 4.5 \mathrm{hr}^{\times 8}$ was the only regime which increased MMP-3 expression $(P<0.05$; Figure $6 \mathrm{~b})$. In unstrained constructs, treatment with telopeptides or $\mathrm{NH}_{2}$-FN-f for 6 or 48 hours increased MMP-3 


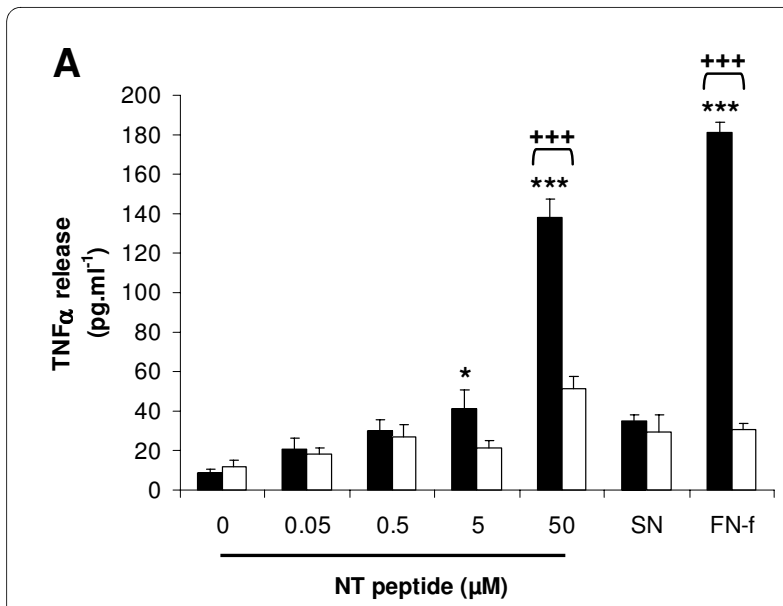

B
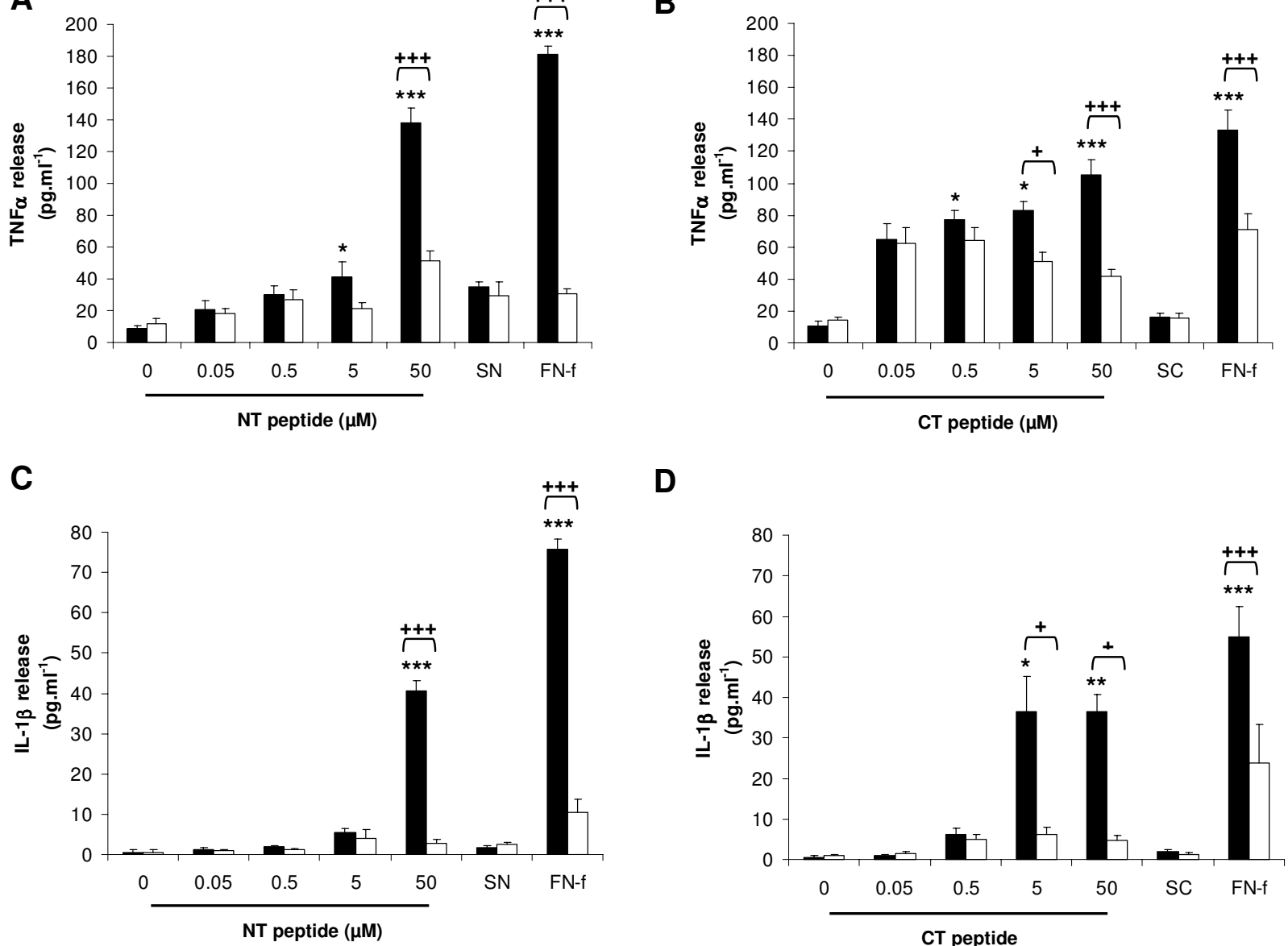

D

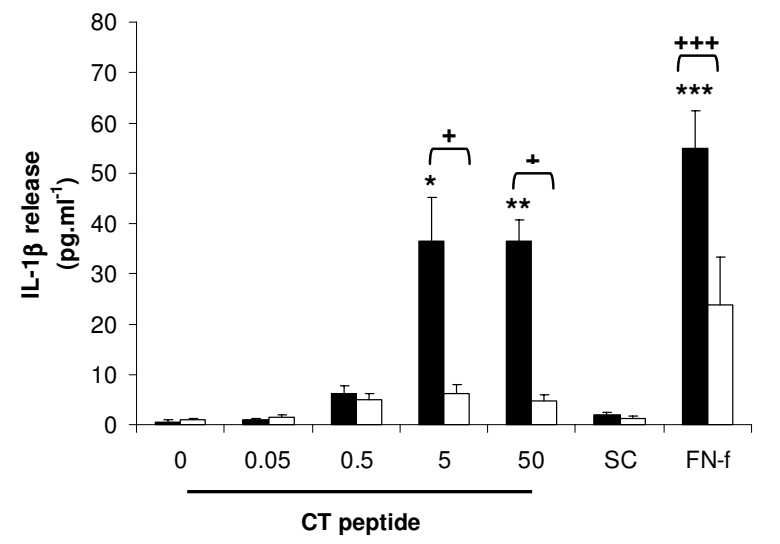

Telopeptide or FN-f

Telopeptide or FN-f + 1400W

Figure 3 Dose-response effect of NT and CT telopeptides. Constructs were cultured with NT ( 0.05 to $50 \mu \mathrm{M})$ or CT ( 0.05 to $50 \mu \mathrm{M})$ peptides under free-swelling conditions in the presence or absence of $1 \mathrm{mM} 1400 \mathrm{~W}$ for 48 hours: (a) TNFa release and $(\mathbf{b}) \mathrm{IL}-1 \beta(\mathrm{n}=6)$. A scrambled form of the NT $(\mathrm{SN})$ and $\mathrm{CT}(\mathrm{SC})$ peptide were used as negative controls (both at $50 \mu \mathrm{M})$. An NH $\mathrm{NH}_{2}-\mathrm{FN}-\mathrm{f}(1 \mu \mathrm{M})$ was used as a positive control. $\left(^{*}\right)$ indicates significant comparisons for 0 vs fragment; (+) indicates significant comparisons for fragment vs fragment $+1400 \mathrm{~W}(n=6)$.

expression (all $P<0.001$; Figure $6 \mathrm{a}$ and $6 \mathrm{~b}$, respectively). This effect was inhibited under all compression regimes and/or culture with the iNOS inhibitor. Under no treatment conditions, compression for C6 or C48 hours did not significantly influence MMP-13 expression (Figure $6 \mathrm{c}, \mathrm{d})$. In unstrained constructs, the presence of the telopeptides or $\mathrm{NH}_{2}$-FN-f increased MMP-13 at 6 hours (all $P<0.01$; Figure 6c) with maximal stimulation at 48 hours (all $P<0.001$; Figure 6d). This effect was inhibited under all compression regimes and/or $1400 \mathrm{~W}$ at 6 or 48 hours. The control SN and SC peptides did not significantly influence MMP-3 or MMP-13 expression in constructs subjected to dynamic compression.

Under no treatment conditions, compression for 10 minutes $/ 5 \mathrm{hr} 50^{\times 1}, 1.5 \mathrm{hr} / 4.5 \mathrm{hr}^{\times 1}$ or C6 hours increased collagen type II and fibronectin expression (Figure 7a and $7 c$, respectively). In unstrained constructs, telopeptides or $\mathrm{NH}_{2}$-FN-f decreased collagen type II and fibronectin expression at six hours (both $P<0.001$; Figure $7 \mathrm{a}, \mathrm{c}$ ). This effect was partially reversed under all compression regimes and/or $1400 \mathrm{~W}$ for peptide or fragment treated constructs. At specific compression regimes, the iNOS inhibitor increased fibronectin expression in the presence of the NT peptide and FN-f at 48 hours (Figure 7d). We did not detect any significant changes in collagen type II or fibronectin expression under all test conditions at 48 hours (Figure $7 \mathrm{~b}$ and $7 \mathrm{~d}$, respectively). The only exception was with the $\mathrm{NH}_{2}$-FN-f which increased fibronectin expression in unstrained constructs and was partially reversed by all compression regimes (Figure $7 \mathrm{~d}$ ). 
A

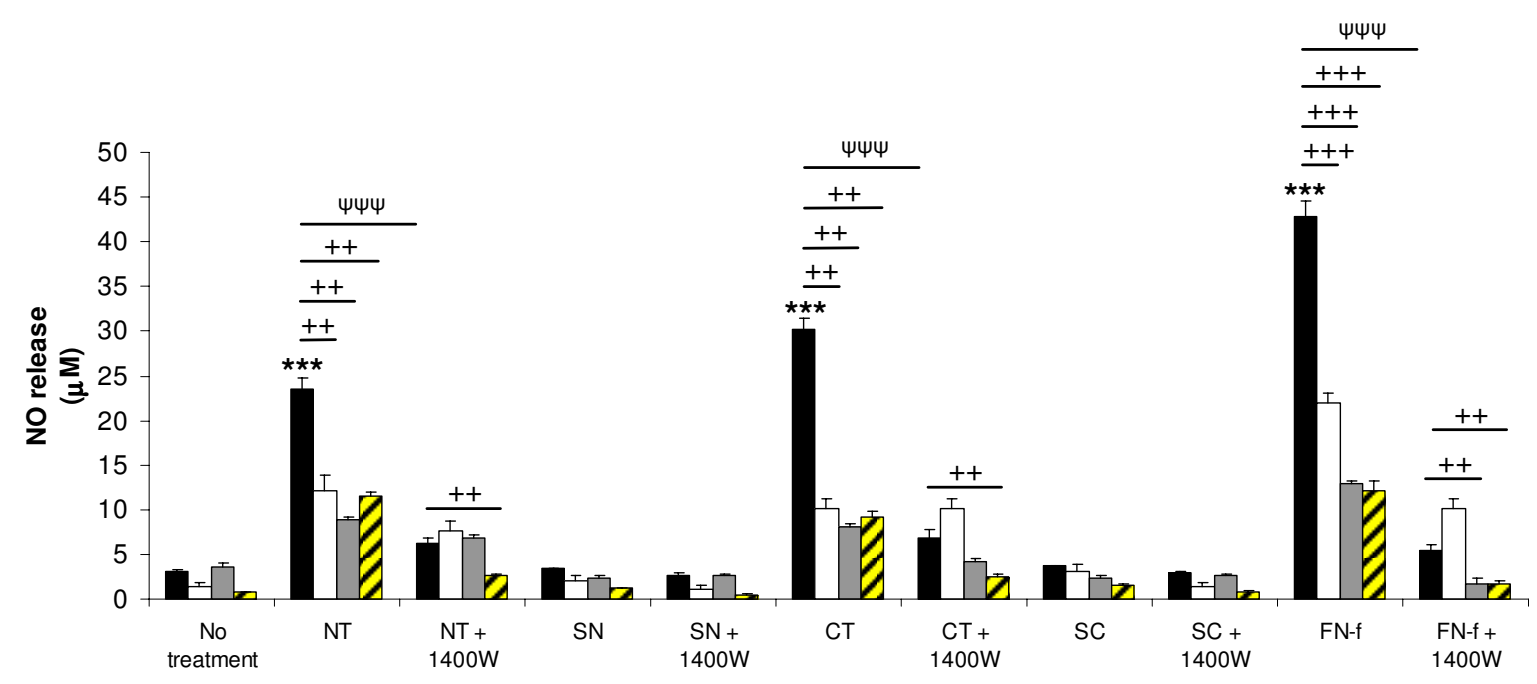

B

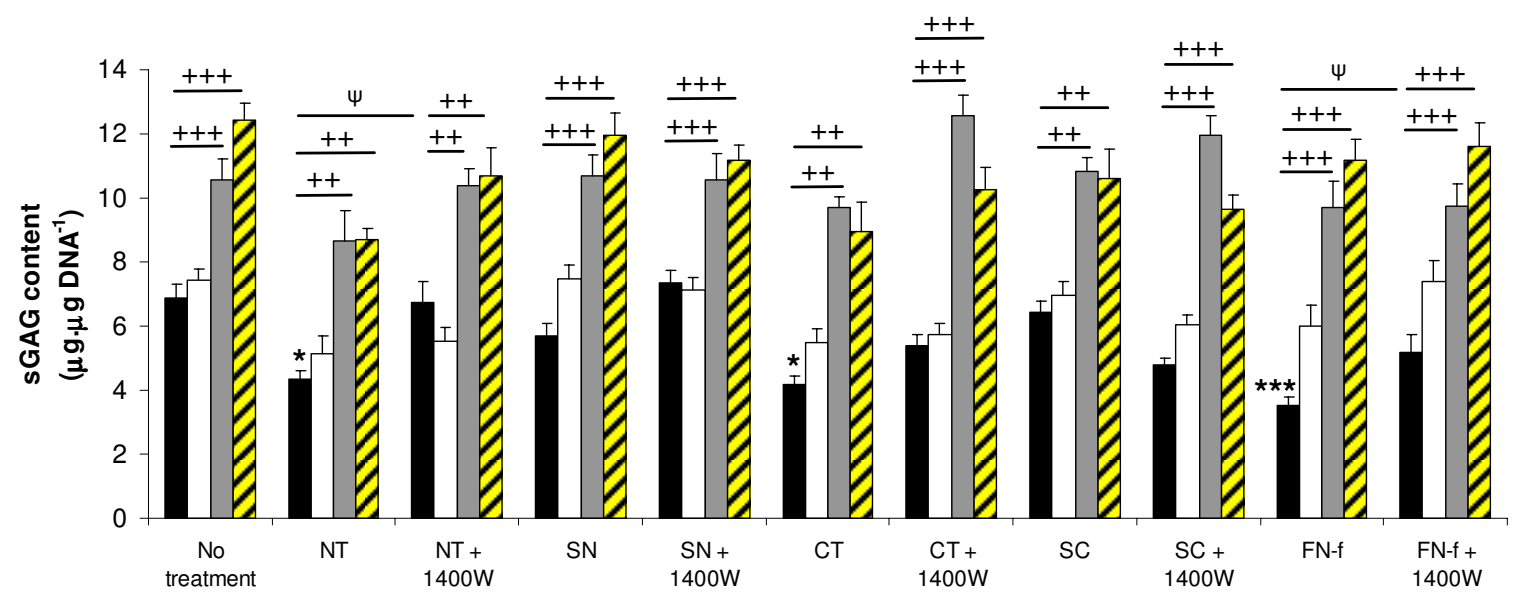

Unstrained

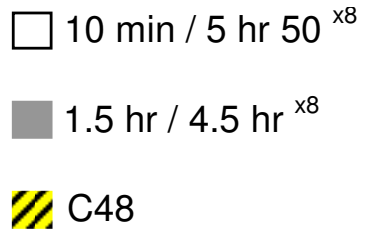

Strained

Figure 4 Effect of NT and CT telopeptides and dynamic compression (15\%, $1 \mathrm{~Hz}$ ) on NO release (a) and sGAG content (b). Unstrained and strained constructs were cultured with $50 \mu \mathrm{M}$ NT or CT peptide and/or $1 \mathrm{mM} 1400 \mathrm{~W}$ for 48 hours $(n=8)$. SN and SC peptides $(50 \mu M)$ were used as negative controls. $\mathrm{NH}_{2}-\mathrm{FN}-\mathrm{f}(1 \mu \mathrm{M})$ was used as a positive control. $\left(^{*}\right)$ indicates significant comparisons in unstrained constructs for no treatment vs fragment; $(\psi)$ indicates significant comparisons in unstrained constructs for fragment vs fragment $+1400 W_{;}+P<0.05,++P<0.01,+++P<0.001$ indicates significant comparisons between treatment conditions as shown $(n=6)$.

\section{Discussion}

OA is a complex disease and involves both biochemical and mechanical factors which influence disease progression. The primary causative factors are due to an increase in the levels of inflammatory mediators which contribute to an imbalance between anabolic and catabolic signal- ling processes. There is evidence demonstrating that the enhanced levels of FN-fs and Col-fs will initiate matrix destruction and accelerate production of catabolic mediators [1-3,32-36]. Despite advances in our understanding of the role of matrix fragments in cartilage biology, few research groups have examined whether mechanical sig- 
A

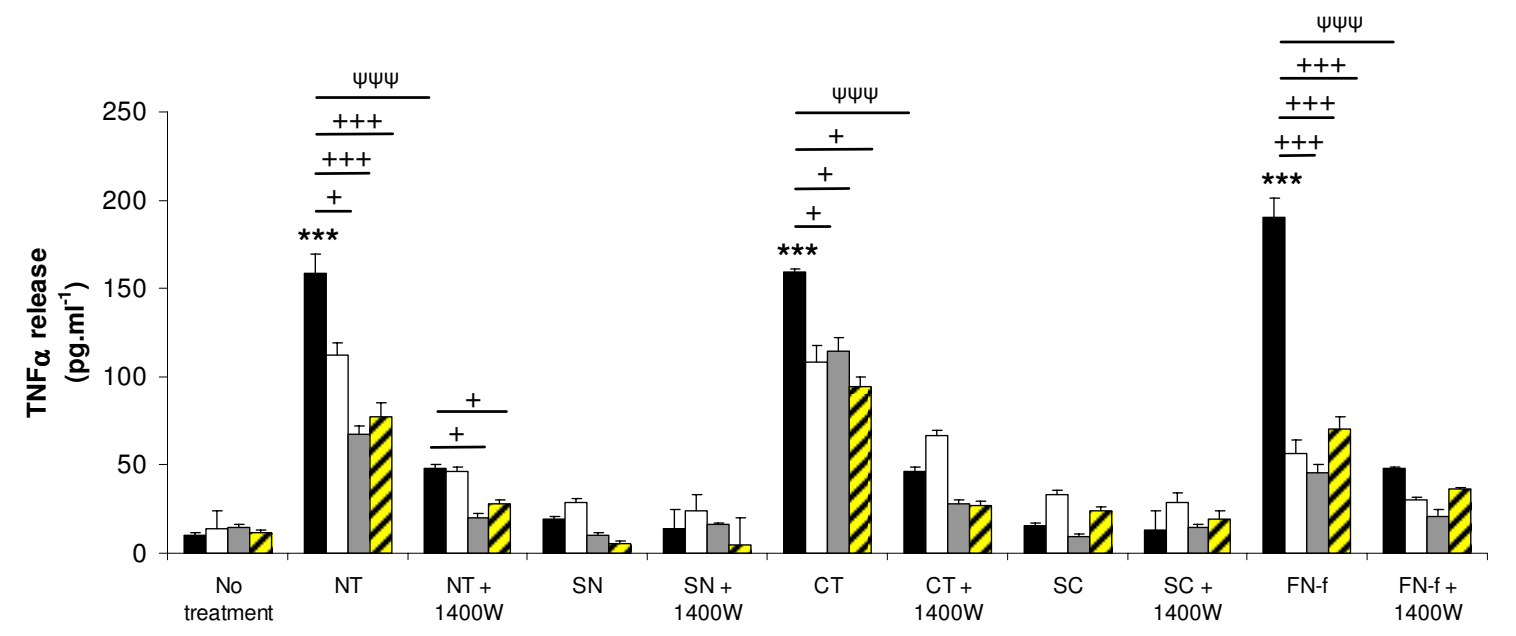

B

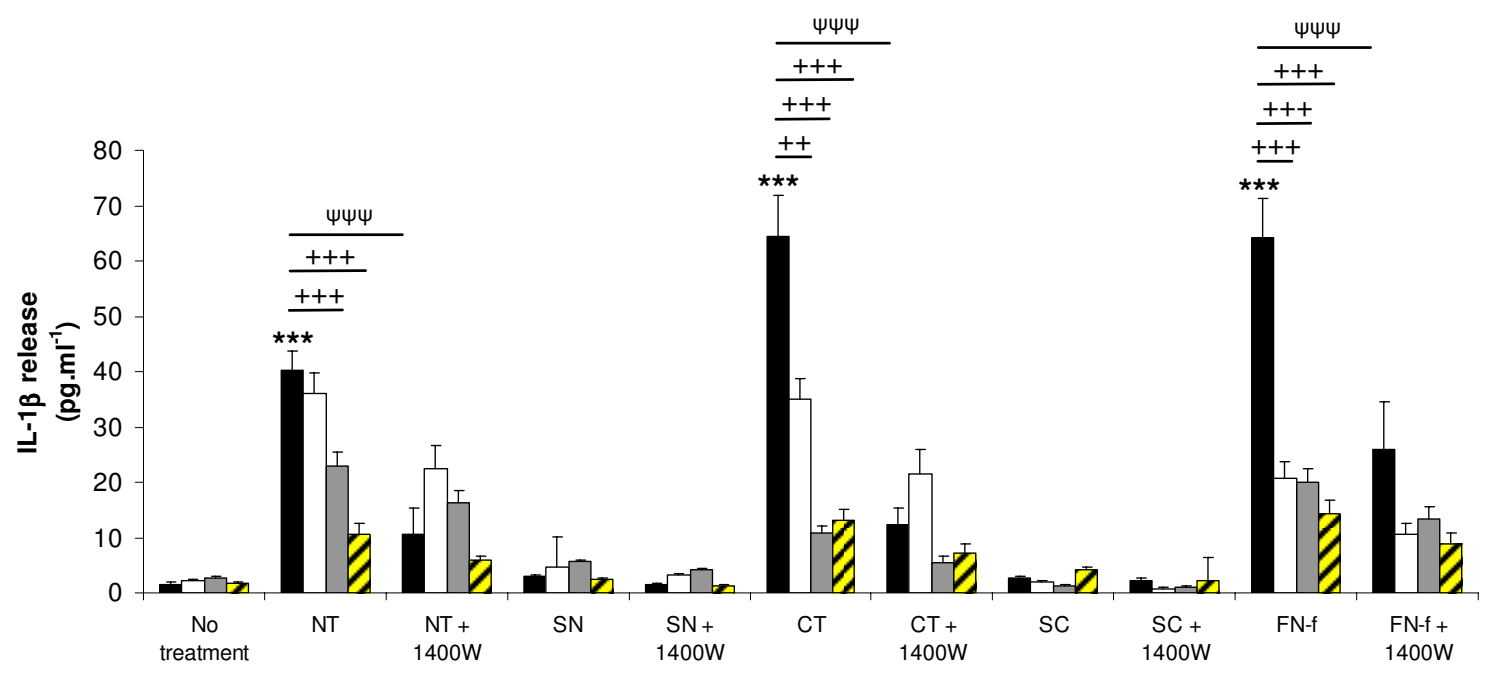

Unstrained

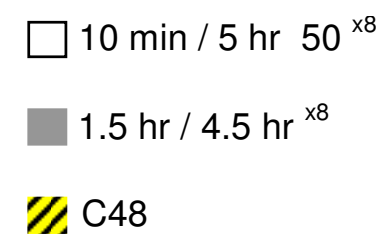

\section{Strained}

Figure 5 Effect of NT and CT telopeptides and dynamic compression $(15 \%, 1 \mathrm{~Hz})$ on cytokine production. Unstrained and strained constructs were cultured with NT or CT peptide (both $50 \mu \mathrm{M})$ and/or $1400 \mathrm{~W}(1 \mathrm{mM})$ for 48 hours: (a) TNFa release and (b) $\mathrm{L}-1 \beta$ release $(n=8)$. SN and SC peptides $(50 \mu \mathrm{M})$ were used as negative controls. $\mathrm{NH}_{2}-\mathrm{FN}-\mathrm{f}(1 \mu \mathrm{M})$ was used as a positive control. $\left(^{*}\right)$ indicates significant comparisons in unstrained constructs for no treatment vs fragment; $(\psi)$ indicates significant comparisons in unstrained constructs for fragment vs fragment $+1400 \mathrm{~W} ;+P<0.05,++P<$ $0.01,+++P<0.001$ indicates significant comparisons between treatment conditions as shown $(n=8)$.

nals could interfere with the fragment-induced pathways and modulate cell function through a positive feedback loop. In addition, pharmacological treatments have attempted to manipulate the inflammatory pathways during late stage OA $[37,38]$. Efforts have been largely disap- pointing due to lack of studies identifying the molecular/ mechanical signals which control matrix repair and/or degradation in early disease states. Our understanding of the early mechanopathophysiology is poor, particularly in terms of reliable biomarkers. Thus, studies which investi- 

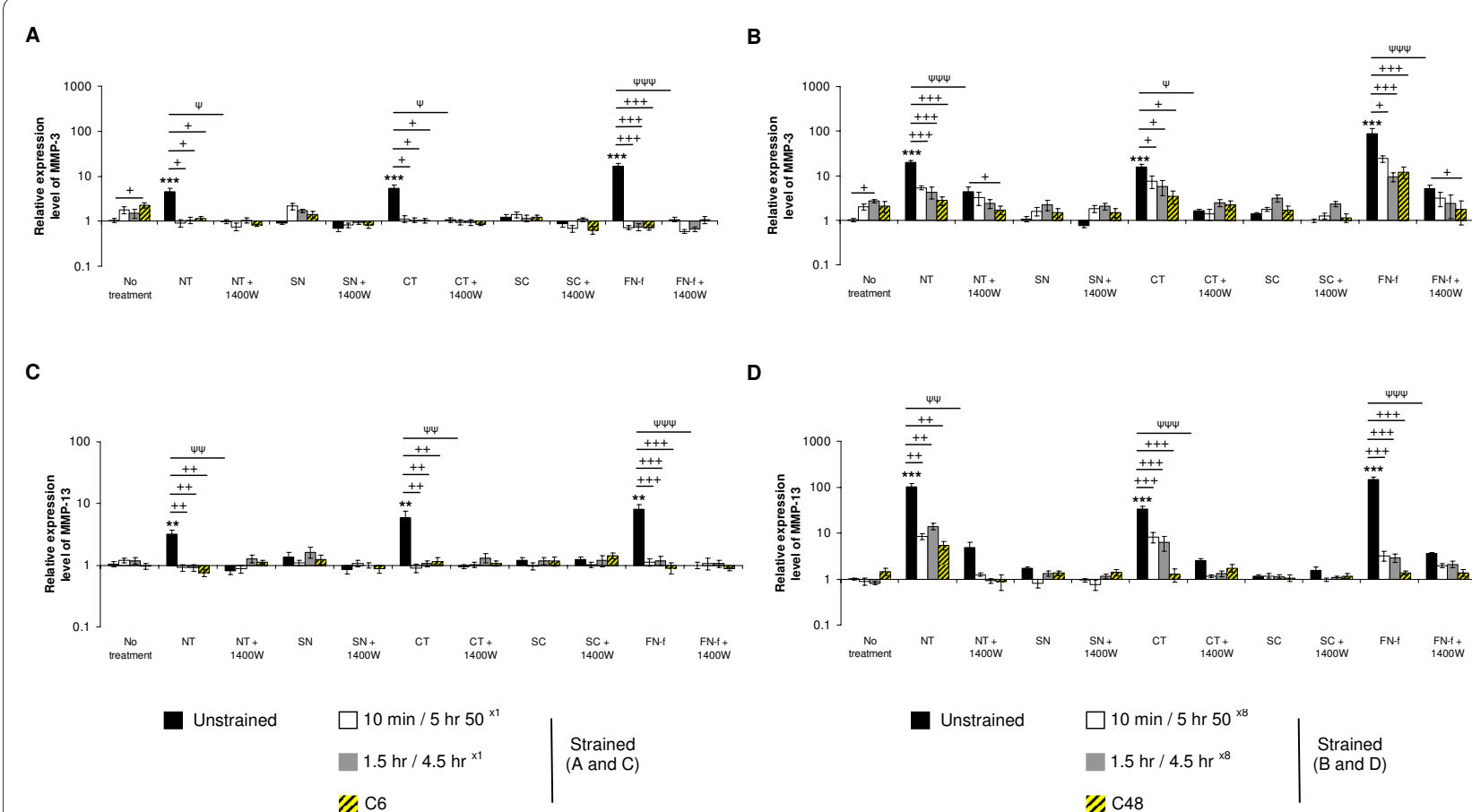

D

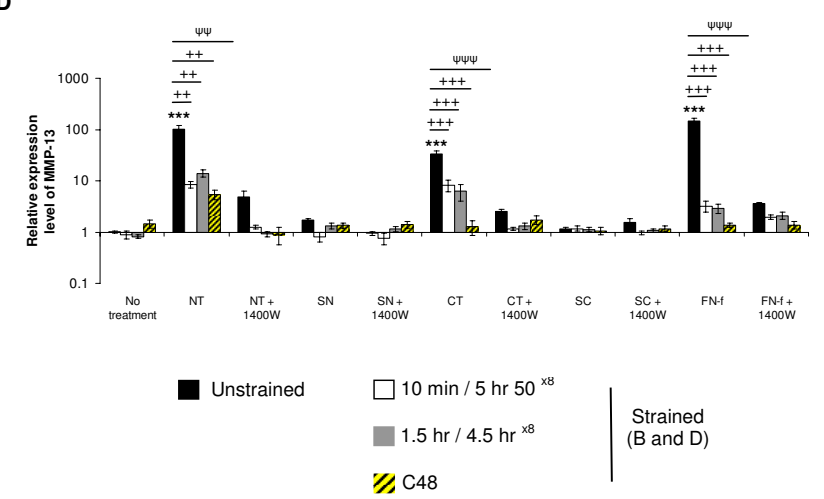

Figure 6 Effect of NT and CT telopeptides and dynamic compression $(15 \%, 1 \mathrm{~Hz})$ on gene expression. Unstrained and strained constructs were cultured with either NT or CT peptide (both $50 \mu \mathrm{M}$ ) and/or $1400 \mathrm{~W}(1 \mathrm{mM})$ for 6 or 48 hours, respectively: (a and b) MMP-3 (c and d) and MMP-13 (n $=8)$. SN and SC peptides $(50 \mu \mathrm{M})$ were used as negative controls. $\mathrm{NH}_{2}-\mathrm{FN}-\mathrm{f}(1 \mu \mathrm{M})$ was used as a positive control. (*) indicates significant comparisons in unstrained constructs for no treatment vs fragment; $(\psi)$ indicates significant comparisons in unstrained constructs for fragment vs fragment +1400 $W_{i}+P<0.05,++P<0.01,+++P<0.001$ indicates significant comparisons between treatment conditions as shown $(n=8)$.

gate factors for early treatments and preserve the biomechanical function of the joint are both worthwhile and necessary.

The present study characterised the effect of Col-fs containing the NT or CT telopeptide regions on catabolic and anabolic activities and compared the response to the $\mathrm{NH}_{2}$-FN-f utilising the chondrocyte/agarose model. In dose-response studies, 48 hours of treatment with the NT or CT peptides increased NO production, enhanced IL$1 \beta$ and TNF $\alpha$ production and inhibited sGAG content in a concentration-dependent manner. Gene expression of MMP-3 and MMP-13 was detected at 6 hours with maximal induction at 48 hours in unstrained constructs treated with telopeptides or the $\mathrm{NH}_{2}$-FN-f. We provide evidence that in some instances, a high concentration of NT or CT peptide $(50 \mu \mathrm{M})$ was just as effective in stimulating catabolic activities as the $\mathrm{NH}_{2}$-FN-f $(1 \mu \mathrm{M})$. The concentrations used in the present study are comparable to previous work which reported fragments encompassing the amino-terminal $29 \mathrm{kDa} F N$-f vary in concentration between 0.1 and $1 \mu \mathrm{M}$ in human OA synovial fluids and NT and CT peptides were found to be $3 \mu \mathrm{m}$ in a rabbit OA model [16,39-41]. We used a telopeptide concentration which represents a diseased state, so it is highly likely we are seeing maximum catabolic effects by the
Col-fs. In addition, the iNOS inhibitor blocked fragmentinduced catabolic activities and stimulated sGAG content. Col-fs may therefore serve to increase catabolic activities through common pathways involving NO which results in the subsequent production of MMPs and cytokines. Our findings are supported by previous studies which demonstrate the induction of MMPs and cytokines in chondrocyte monolayers and cartilage explants cultured with collagen derived peptides [20-23]. Furthermore, human chondrocytes treated with type II collagen caused sequential induction of MMPs (MMP-1, 3, 13 and 14) and cytokine production (IL-1 $\beta$, IL-6, IL-8) followed by release of Col-fs from mature collagen fibres [42]. The catabolic process involved activation of p38 MAPK and NFKB leading to the production of MMPs and cytokines [42]. Overproduction of the matrix degrading enzymes will additionally release telopeptides from the triple helix, generating further Col-fs [43]. In OA, the enhanced action of MMPs on matrix proteins will generate several types of fragments released through different enzymatic pathways. It is plausible that fragments from collagen or fibronectin may arise from the degenerating matrix and promote a catabolic state through activation of common pathways. This is turn generates more matrix fragments which amplifies MMPs in a positive feedback loop $[9,12]$. 


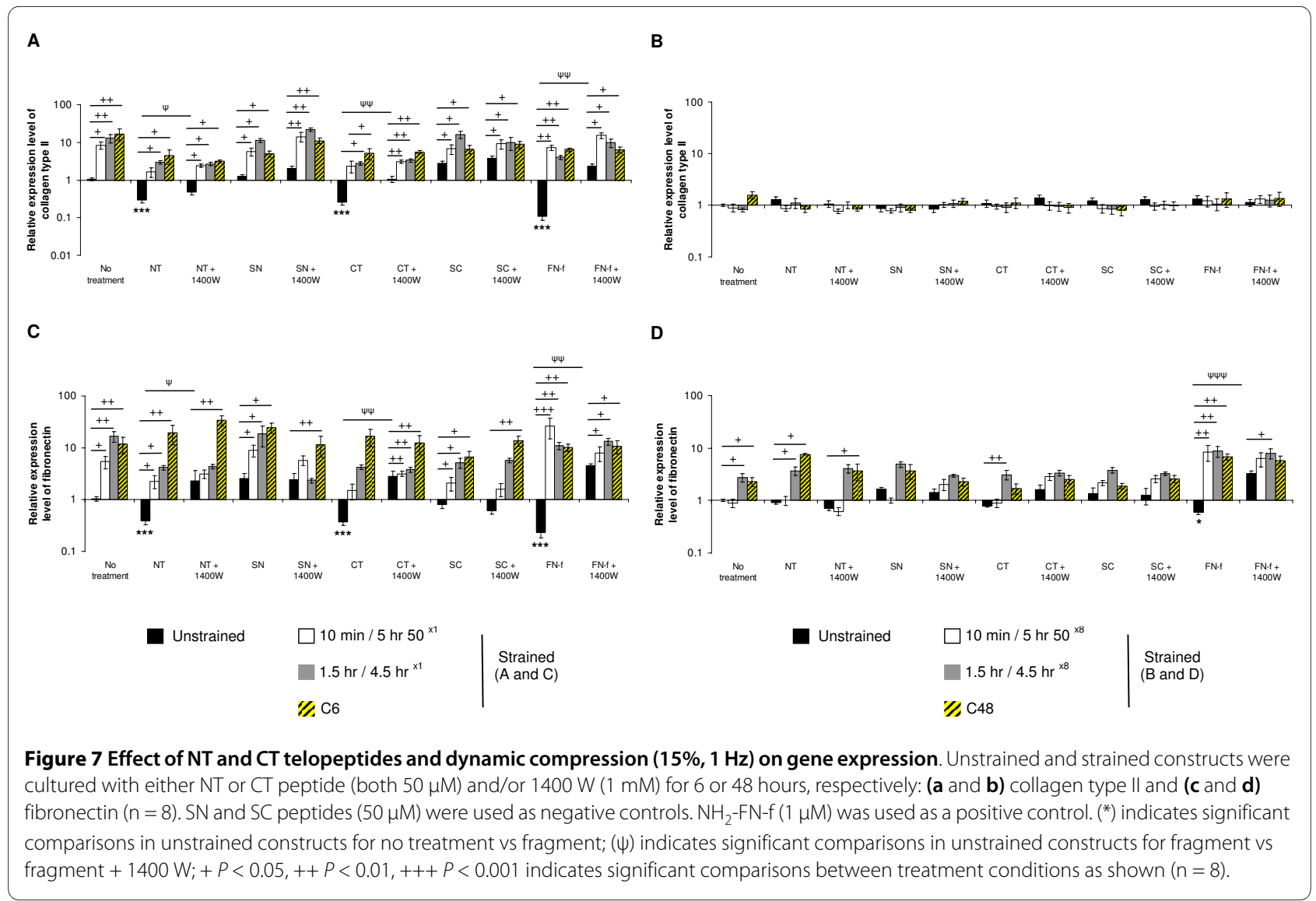

A key question is whether a threshold concentration of fragmented matrix proteins exists, such that low levels initiate early reparative events and switch to catabolic insults at a later stage when the concentration increases above a certain level. These points raise important questions which should be investigated further.

We next examined whether dynamic compression could modulate the catabolic response induced by the fragments in constructs cultured in a bioreactor. We compared a continuous compression regime (C6 or C48) with an intermittent protocol repeated once (10 minutes/ $5 \mathrm{hr} 50^{\times 1}, 1.5 \mathrm{hr} / 4.5 \mathrm{hr}^{\times 1}$ ) or eight times (10 minutes/5 hr $50 \times 8,1.5 \mathrm{hr} / 4.5 \mathrm{hr}^{\times 8}$ ) during a 6 or 48 hour culture period. Our findings indicate that continuous compression was just as effective in downregulating fragment-induced $\mathrm{NO}$ release as intermittent compression and the response could be further downregulated with the iNOS inhibitor. In contrast, modulation of MMPs and cytokines by mechanical loading were dependent on the length and type of compression regime applied. More specifically, increasing the total number of compression cycles from 4800 to 172800 clearly had a greater inhibitory effect on cytokine production and MMP-3 and 13 expression in constructs stimulated with telopeptides. This is in contrast to constructs cultured with $\mathrm{NH}_{2}$-FN-f where the shortest duration of intermittent compression was just as effective in inhibiting cytokine production and MMP expression when compared to longer cycles. Our findings indicate that co-stimulation with dynamic compression and the iNOS inhibitor was marginally better at downregulating catabolic activities for some of the fragment conditions examined. The opposite effect was found for anabolic activities, such that longer periods of compression resulted in a greater magnitude of stimulation of sGAG content and expression of collagen type II and fibronectin even in the presence of fragments. The importance of these findings emphasises the nature of the mechanical stimulus in controlling catabolic and anabolic activities in chondrocytes. In a previous study utilising the cell/agarose model, the number of cycles of compression, applied in a continuous or intermittent manner was shown to be important in determining the nature of the chondrocytes metabolic response [44]. For instance, frequent bursts of intermittent compression for longer time periods favoured proteoglycan synthesis whereas shorter bursts of intermittent compression tended to favour cell proliferation. A similar response was described by other research groups which showed that the biochemical response was dependent on the duration and type of compression regime employed [45-48]. We could there- 
fore speculate that the intermittent loading regime used in the present study mimics the physiological loading environment of cartilage. In contrast, the continuous compression regime could be interpreted as an excessive or injurious response since these conditions favoured rapid matrix turnover $[49,50]$.

In healthy tissue, a small proportion of collagen and fibronectin levels will maintain normal matrix turnover and be released due to proteolytic digestion by MMPs [49]. In the present study, some of the enhanced collagen type II and fibronectin synthesis by dynamic compression could be an initial response at repair which may later give rise to catabolic activities involving increased synthesis of MMPs and released fragments. There is good evidence that mechanical loading conditions that mimic injury and overloading which contribute to altered patterns of load can accelerate mild damage with an early rebuilding phase by increasing MMPs and metabolic activity [5155]. It is conceivable that the rebuilding phase may occur indirectly through the effect of altered patterns of mechanical loading by increasing the production of growth factors (TGF $\beta 1$, IGF-1, bFGF), anti-inflammatory cytokines (IL-4) or soluble mediators (Substance P, glutamate) [56-60]. Furthermore, there is evidence that integrins serve as receptors for both mechanical loading and matrix fragments implicating overlapping pathways for these signals $[15,19,60,61]$. Integrin-mediated mechanotransduction will contribute to chondroprotective events resulting in the cells' attempt to stimulate anabolic processes locally and assist in tissue remodelling [60]. This response will at least, in part, be dependent on the type of mechanical loading regime, its duration and whether loading was applied during the early or late stage of the disease process. Thus, conditions such as obesity or trauma that represent excessive or injurious loading will increase catabolic activities and accelerate matrix damage $[48,62,63]$. This disruption of matrix composition will contribute to abnormal biomechanics thereby increasing NO production, reactive oxygen species and chondrocyte death in vivo $[64,65]$.

In summary, the present study demonstrates that mechanical loading modulates the catabolic and anabolic response of chondrocytes stimulated with collagen and FN-fs. The catabolic response was dependent on the concentration and type of fragment such that for conditions which represent cartilage degradation, collagen telopeptides were just as potent in increasing catabolic activities as the FN-fs. Mechanical loading could reverse the catabolic process induced by the fragments and enhance anabolic activities. However, the response was dependent on the length and type of compression regime applied. Furthermore, co-stimulation by dynamic compression in the presence of the iNOS inhibitor led to further time-dependent increases in the expression of matrix proteins and downregulation of cytokines and MMPs, implicating NO dependent pathways. The ability of chondrocytes to interact with matrix fragments and respond to biomechanical signals may be a key initiating event in the disease process. Further studies are needed to examine the complexity of the sequence of signalling events which interplay with biomechanical and matrix fragment signals for early OA therapeutic intervention.

\section{Conclusions}

Telopeptides have dose-dependent catabolic activities similar to $\mathrm{FN}-\mathrm{fs}$ and increase the production of $\mathrm{NO}$, cytokines and MMPs. Catabolic activities were inhibited by dynamic compression or by the presence of the iNOS inhibitor, linking reparative activities by both types of stimuli. Future investigations which examine the signalling cascades of chondrocytes in response to matrix fragments with mechanical influences may provide useful information for early OA treatments.

\begin{abstract}
Abbreviations
Col-f: collagen fragment; $C_{t}$ cycle threshold; $C T$ : C-terminal telopeptide; DMEM: Dulbecco's Modified Eagle's Medium; EBSS: foetal calf serum; FCS: foetal calf serum; FN-f: fibronectin fragment; iNOS: inducible nitric oxide synthase; IL-1 $\beta$ : interleukin-1 $\beta$; MAPK: mitogen activated protein kinase; MMPs: matrix metalloproteinases; NFkB: nuclear factor-kappa B; NO: nitric oxide; NoRT: no reverse transcriptase; NT: N-terminal telopeptide; OA: osteoarthritis; $\mathrm{qPCR}$ : quantitative polymerase chain reaction; sGAG: sulphated glycosaminoglycan; TNFa: tumour necrosis factor-a.
\end{abstract}

\section{Competing interests}

The authors declare that they have no competing interests.

\section{Authors' contributions}

TC supervised RS, SR, CT and NW who carried out experiments and analysis. TC and GH participated in the experimental design, data analysis and drafted the manuscript. All authors read and approved the final manuscript.

\section{Acknowledgements}

This work was supported by a Royal Society international grant awarded to Dr Tina Chowdhury. She especially thanks Bastian Pfeiffer for his excellent technical assistance with the bioreactor studies and the German Federal Ministry of Education and Research for support with resources (BMBF, PtJ-Bio, 0313909).

\section{Author Details}

'School of Engineering and Materials Science, Queen Mary University of London, Mile End Road, London, E1 4NS, UK, 2Department of Cell Techniques and Applied Stem Cell Biology, University of Leipzig, Deutscher Platz 5, Leipzig, 04103, Germany and ${ }^{3}$ Department of Biochemistry and Molecular Biology, University of North Dakota School of Medicine and Health Sciences, Box 9037, Grand Forks, ND 58202, USA

Received: 20 October 2009 Revised: 26 January 2010 Accepted: 12 May 2010 Published: 12 May 2010

\section{References}

1. Homandberg GA: Potential regulation of cartilage metabolism in osteoarthritis by fibronectin fragments. Fundamental Pathways in Osteoarthritis Front Biosci 1997:713-730.

2. Yasuda T: Cartilage destruction by matrix degradation products. Mod Rheumatol 2006, 16:197-205.

3. Homandberg GA, Ding L, Guo D: Extracellular matrix fragments as regulators of cartilage metabolism in health and disease. Curr Rheumatol Rev 2007, 3:183-196. 
4. Lorenzo P, Bayliss MT, Heinegard D: Altered patterns and synthesis of extracellular matrix macromolecules in early OA. Matrix Biol 2004, 23:381-391

5. Griffin TM, Guilak F: The role of mechanical loading in the onset and progression of osteoarthritis. Exerc Sport Sci Rev 2005, 33:195-200.

6. Guilak F, Fermor B, Keefe FJ, Kraus VB, Olson SA, Pisetsky DS, Setton LA, Weinberg JB: The role of biomechanics and inflammation in cartilage repair and injury. Clin Orthop Relat Res 2004:17-26.

7. Loeser RF: Molecular mechanisms of cartilage destruction: mechanics, inflammatory mediators, and aging collide. Arthritis Rheum 2006, 54:1357-1360

8. Xie D, Hui F, Homandberg GA: Fibronectin fragments alter matrix protein synthesis in cartilage tissue cultured in vitro. Arch Biochem Biophys 1993, 307:110-118

9. Xie D, Hui F, Homandberg GA: Cartilage chondrolysis by fibronectin fragments is associated with release of several proteinases: stromelysin plays a major role in chondrolysis. Arch Biochem Biophys 1994, 311:205-212.

10. Homandberg GA, Hui F: Association of proteoglycan degradation with catabolic cytokine and stromelysin release from cartilage cultured with fibronectin fragments. Arch Biochem Biophys 1996, 334:325-331.

11. Homandberg GA, Hui F, Wen C, Purple C, Bewsey K, Koepp H, Huch K, Harris A: Fibronectin-fragment-induced cartilage chondrolysis is associated with release of catabolic cytokines. Biochem J 1997, 321:751-757.

12. Homandberg GA, Wen C, Hui F: Cartilage damaging activities of the fibronectin fragments derived from cartilage and synovial fluid. Osteoarthritis Cartilage 1998, 6:231-244

13. Gemba T, Valbracht J, Alsalmeh S, Lotz M: Focal adhesion kinase and mitogen-activated protein kinases are involved in chondrocyte activation by the $29-\mathrm{kDa}$ amino-terminal fibronectin fragment. $J$ Biol Chem 2002, 277:907-911.

14. Pichika R, Homandberg GA: Fibronectin fragments elevate nitric oxide (NO) and inducible NO synthetase (iNOS) levels in bovine cartilage and iNOS inhibitors block fibronectin fragment mediated damage and promote repair. Inflamm Res 2004, 53:405-412.

15. Forsyth CB, Pulai J, Loeser RF: Fibronectin fragments and blocking antibodies to alpha2beta 1 and alpha5beta 1 integrins stimulate mitogen-activated protein kinase signaling and increase collagenase 3 (matrix metalloproteinase 13) production by human articular chondrocytes. Arthritis Rheum 2002, 46:2368-2376.

16. Homandberg GA, Meyers R, Xie D: Fibronectin fragments cause chondrolysis of bovine articular cartilage slices in culture. $\mathrm{JBio} / \mathrm{Chem}$ 1992, 267:3597-3604.

17. Yasuda T, Kakinuma T, Julovi SM, Yoshida M, Hiramitsu T, Akiyoshi M, Nakamura T: $\mathrm{COOH}$-terminal heparin-binding fibronectin fragment induces nitric oxide production in rheumatoid cartilage through CD44. Rheumatology 2004, 43:1116-1120.

18. Pulai II, Chen H, Im HJ, Kumar S, Hanning C, Hegde PS, Loeser RF: NFkappa B mediates the stimulation of cytokine and chemokine expression by human articular chondrocytes in response to fibronectin fragments. J Immuno/ 2005, 174:5781-5788.

19. Ding $L$, Guo D, Homandberg GA: Fibronectin fragments mediate matrix metalloproteinase upregulation and cartilage damage through proline rich tyrosine kinase 2, c-src, NF-kappaB and protein kinase Cdelta. Osteoarthritis Cartilage 2009, 17:1385-1392.

20. Lucic D, Mollenhauer J, Kilpatrick KE, Cole AA: N-telopeptide of type II collagen interacts with annexin $\mathrm{V}$ on human chondrocytes. Connect Tissue Res 2003, 44:225-239.

21. Jennings L, Wu L, King KB, Hämmerle H, Cs-Szabo G, Mollenhauer J: The effects of collagen fragments on the extracellular matrix metabolism of bovine and human chondrocytes. Connect Tissue Res 2001, 42:71-86.

22. Fichter M, Körner U, Schömburg J, Jennings L, Cole AA, Mollenhauer J: Collagen degradation products modulate matrix metalloproteinase expression in cultured articular chondrocytes. J Orthop Res 2006, 24:63-70.

23. Guo D, Ding L, Homandberg GA: Telopeptides of type II collagen upregulate proteinases and damage cartilage but are less effective than highly active fibronectin fragments. Inflamm Res 2009, 58:161-169.

24. Raveenthiran SP, Chowdhury TT: Dynamic compression inhibits fibronectin fragment induced iNOS and COX-2 expression in chondrocyte/agarose constructs. Biomech Model Mechanobiol 2009, 8:273-283.

25. Lee DA, Bader DL: Compressive strains at physiological frequencies influence the metabolism of chondrocytes seeded in agarose. J Orthop Res 1997, 15:181-188.

26. Lee DA, Knight MM: Mechanical loading of chondrocytes embedded in 3D constructs: in vitro methods for assessment of morphological and metabolic response to compressive strain. Methods Mol Med 2004 100:307-324.

27. Schulz RM, Wüstneck N, van Donkelaar CC, Shelton JC, Bader A: Development and validation of a novel bioreactor system for load- and perfusion-controlled tissue engineering of chondrocyte-constructs. Biotechnol Bioeng 2008, 101:714-728.

28. Lee DA, Brand J, Salter DM, Akanji OO, Chowdhury TT: Quantification of mRNA using real-time PCR and western blot analysis of MAPK events in chondrocyte/agarose constructs. Methods Mol Med 2010 in press.

29. Pfaff MW, Horgan GW, Dempfle L: Relative expression software tool (REST) for group wise comparison and statistical analysis of relative expression results in real time PCR. Nucleic Acids Res 2002, 30:e36.

30. Chowdhury TT, Bader DL, Lee DA: Dynamic compression inhibits the synthesis of nitric oxide and $\mathrm{PGE}_{2}$ by IL-1 $\beta$ stimulated chondrocytes cultured in agarose constructs. Biochem Biophys Res Commun 2001, 285:1168-1174.

31. Chowdhury TT, Bader DL, Lee DA: Dynamic compression counteracts IL$1 \beta$ induced release of nitric oxide and $\mathrm{PGE}_{2}$ by superficial zone chondrocytes cultured in agarose constructs. Osteoarthritis Cartilage 2003, 11:688-696.

32. Jung M, Christgau S, Lukoschek M, Henriksen D, Richter W: Increased urinary concentration of collagen type II C-telopeptide fragments in patients with osteoarthritis. Pathobiology 2004, 71:70-76.

33. Carnemolla B, Cutolo M, Castellani P, Balza E, Raffanti S, Zardi L: Characterization of synovial fluid fibronectin from patients with rheumatic inflammatory diseases and healthy subjects. Arthritis Rheum 1984, 27:913-921.

34. Jones KL, Brown M, Ali SY, Brown RA: An immunohistochemical study of fibronectin in human osteoarthritic and disease-free articular cartilage. Ann Rheum Dis 1987, 46:809-815.

35. Brown RA, Jones KL: Fibronectin synthesis and release in normal and $\mathrm{OA}$ human cartilage. Eur J Exp Musculoskel Res 1992, 1:25-32.

36. Garnero P, Ayral X, Rousseau JC, Christgau S, Sandell LJ, Dougados M, Delmas PD: Uncoupling of type II collagen synthesis and degradation predicts progression of joint damage in patients with knee osteoarthritis. Arthritis Rheum 2002, 46:2613-2624.

37. Felson DT, Kim YJ: The futility of current approaches to chondroprotection. Arthritis Rheum 2007, 56:1378-1383.

38. Dieppe P: Disease modification in osteoarthritis: are drugs the answer? Arthritis Rheum 2005, 52:1956-1959.

39. Xie DL, Meyers R, Homandberg GA: Fibronectin fragments in osteoarthritic synovial fluid. J Rheumatol 1992, 19:1448-1452.

40. Billinghurst RC, Dahlberg L, lonescu M, Reiner A, Bourne R, Rorabeck C, Mitchell P, Hambor J, Diekmann O, Tschesche H, Chen J, Van Wart H, Poole AR: Enhanced cleavage of type II collagen by collagenases in osteoarthritic articular cartilage. J Clin Invest 1997, 99:1534-1545

41. Felice BR, Chichester CO, Barrach HJ: Type II collagen peptide release from rabbit articular cartilage. Ann NY Acad Sci 1999, 878:590-593.

42. Klatt AR, Paul-Klausch B, Klinger G, Kühn G, Renno JH, Banerjee M, Malchau $\mathrm{G}$, Wielckens K: A critical role for collagen II in cartilage matrix degradation: collagen II induces pro-inflammatory cytokines and MMPs in primary human chondrocytes. J Orthop Res 2009, 27:65-70

43. Wu JJ, Lark MW, Chun LE, Eyre DR: Sites of stromelysin cleavage in collagen types II, IX, X, and XI of cartilage. J Biol Chem 1991, 266:5625-5628

44. Chowdhury TT, Bader DL, Shelton JC, Lee DA: Temporal regulation of chondrocyte metabolism in agarose constructs subjected to dynamic compression. Arch Biochem Biophys 2003, 417:105-111.

45. Jeffrey JE, Thomson LA, Aspden RM: Matrix loss and synthesis following a single impact load on articular cartilage in vitro. Biochim Biophys Acta 1997, 1334:223-232

46. Valhmu WB, Stazzone EJ, Bachrach NM, Saed-Nejad F, Fischer SG, Mow VC, Ratcliffe A: Load-controlled compression of articular cartilage inducesa transient stimulation of aggrecan gene expression. Arch Biochem Biophys 1998, 353:29-36. 
47. Ragan PM, Badger AM, Cook M, Chin VI, Gowen M, Grodzinsky AJ, Lark MW: Down-regulation of chondrocyte aggrecan and type-II collagen gene expression correlates with increases in static compression magnitude and duration. J Orthop Res 1999, 17:836-842.

48. De Croos JN, Dhaliwal SS, Grynpas MD, Pilliar RM, Kandel RA: Cyclic compressive mechanical stimulation induces sequential catabolic and anabolic gene changes in chondrocytes resulting in increased extracellular matrix accumulation. Matrix Biol 2006, 25:323-331.

49. Blain EJ: Mechanical regulation of MMPs. Front Biosci 2007, 12:507-527.

50. Blain EJ, Mason DJ, Duance VC: The effect of cyclical compressive loading on gene expression in articular cartilage. Biorheology 2003, 40:111-117.

51. Waldman SD, Couto DC, Grynpas MD, Pilliar RM, Kandel RA: A single application of cyclic loading can accelerate matrix deposition and enhance the properties of tissue-engineered cartilage. Osteoarthritis Cartilage 2006, 14:323-330.

52. Kisiday JD, Jin MS, DiMicco MA, Kurz B, Grodzinsky AJ: Effects of dynamic compressive loading on chondrocyte biosynthesis in self assembling peptide scaffolds. J Biomech 2004, 37:595-604.

53. Wong M, Siegrist M, Cao X: Cyclic compression of articular cartilage explants is associated with progressive consolidation and altered expression pattern of extracellular matrix proteins. Matrix Bio/ 1999 18:391-399.

54. Kisiday JD, Lee JH, Siparsky PN, Frisbie DD, Flannery CR, Sandy JD, Grodzinsky AJ: Catabolic responses of chondrocyte-seeded peptide hydrogel to dynamic compression. Ann Biomed Eng 2009, 37:1368-1375.

55. Steinmeyer J, Ackermann B: The effect of continuously applied cyclic mechanical loading on the fibronectin metabolism of articular cartilage explants. Res Exp Med (Berl) 1999, 198:247-260.

56. Bonassar $\sqcup$, Grodzinsky AJ, Srinivasan A, Davila SG, Trippel SB: Mechanical and physicochemical regulation of the action of insulin-like growth factor-I on articular cartilage. Arch Biochem Biophys 2000, 379:57-63.

57. Mauck RL, Nicoll SB, Seyhan SL, Ateshian GA, Hung CT: Synergistic action of growth factors and dynamic loading for articular cartilage tissue engineering. Tissue Eng 2003, 9:597-611.

58. Ramage L, Nuki G, Salter DM: Signalling cascades in mechanotransduction: cell-matrix interactions and mechanical loading. Scand J Med Sci Sports 2009, 19:457-469.

59. Vincent TL, MCLean CJ, Full LE, Peston D, Saklatvala J: FGF-2 is bound to perlecan in the pericellular matrix of articular cartilage, where it acts as a chondrocyte mechanotransducer. Osteoarthritis Cartilage 2007, 15:752-763

60. Millward-Sadler SJ, Salter DM: Integrin-dependent signal cascades in chondrocyte mechanotransduction. Ann Biomed Eng 2004, 32:435-446.

61. Homandberg GA, Costa V, Wen C: Anti-Sense oligonucleotides to the alpha5 integrin subunit suppress cartilage chondrolytic activities of amino-terminal fibronectin fragments. Osteoarthritis Cartilage 2001, 10:381-393.

62. Fitzgerald JB, Jin M, Dean D, Wood DJ, Zheng MH, Grodzinsky AJ: Mechanical compression of cartilage explants induces multiple timedependent gene expression patterns and involves intracellular calcium and cyclic AMP. J Biol Chem 2004, 279:19502-19511.

63. Kurz B, Lemke A, Kehn M, Domm C, Patwari P, Frank EH, Grodzinsky AJ, Schünke M: Influence of tissue maturation and antioxidants on the apoptotic response of articular cartilage after injurious compression. Arthritis Rheum 2004, 50:123-130.

64. Henrotin YE, Bruckner P, Pujol JP: The role of reactive oxygen species in homeostasis and degradation of cartilage. Osteoarthritis Cartilage 2003, 11:747-755

65. Chen CT, Bhargava M, Lin PM, Torzilli PA: Time, stress, and location dependent chondrocyte death and collagen damage in cyclically loaded articular cartilage. J Orthop Res 2003, 21:888-898.

doi: $10.1186 / a r 3009$

Cite this article as: Chowdhury et al., Biomechanical modulation of collagen fragment-induced anabolic and catabolic activities in chondrocyte/agarose constructs Arthritis Research \& Therapy 2010, 12:R82

\section{Submit your next manuscript to BioMed Central and take full advantage of:}

- Convenient online submission

- Thorough peer review

- No space constraints or color figure charges

- Immediate publication on acceptance

- Inclusion in PubMed, CAS, Scopus and Google Scholar

- Research which is freely available for redistribution

Submit your manuscript at www.biomedcentral.com/submit 